\title{
Routine episiotomy versus selective episiotomy in nulliparous women at term-randomized comparative trial
}

\author{
Dipak Kumar Giri, Deboroop Mondal, Snehamay Chaudhuri*
}

Department of Obstetrics and Gynecology, NRS Medical College, Kolkata, West Bengal, India

Received: 25 September 2020

Accepted: 31 October 2020

\section{*Correspondence:}

Dr. Snehamay Chaudhuri,

E-mail: snehamay_chaudhuri_dr@yahoo.com

Copyright: (c) the author(s), publisher and licensee Medip Academy. This is an open-access article distributed under the terms of the Creative Commons Attribution Non-Commercial License, which permits unrestricted non-commercial use, distribution, and reproduction in any medium, provided the original work is properly cited.

\begin{abstract}
Background: Practice of routine episiotomy is debatable. The study aims to compare maternal and fetal outcome in routine episiotomy versus selective episiotomy in nulliparous women delivering at term.

Methods: Two hundred nulliparous women at term were assigned randomly to receive routine or selective episiotomy during delivery. The primary outcome measures were anterior vaginal trauma, $1^{\text {st }}$ degree perineal tear, $2^{\text {nd }}$ degree perineal tear, $3^{\text {rd }}$ degree perineal tear, $4^{\text {th }}$ degree perineal tear and Apgar score at 1 and 5 minutes. Secondary measures of outcome included consumption of analgesics, anal incontinence, urinary incontinence and dyspareunia.

Results: The episiotomy rate was $90 \%$ in routine episiotomy group and $42 \%$ in selective episiotomy group. Occurrence of second-degree perineal injury was more common in routine episiotomy group (90\% versus 64\%; $\mathrm{p}<0.0001)$. However, there was no difference in occurrence of $3^{\text {rd }}$ degree perineal tear among the groups. More women in selective episiotomy group suffered from anterior vaginal wall tear $(22 \%$ versus $54 \%$ p $<0.0001)$. There was no difference among the groups in Apgar score, severity of perineal pain, analgesic use on day 2 of delivery, anal incontinence, urinary incontinence, dyspareunia and NICU admission of the neonate.

Conclusions: Routine episiotomy is associated with a higher incidence of perineal injuries without any added benefit for the mother and the baby.
\end{abstract}

Keywords: Episiotomy, Perineal tear, Routine episiotomy, Selective episiotomy

\section{INTRODUCTION}

Throughout the world the rates of episiotomy increased substantially during early $20^{\text {th }}$ century. It was thought that episiotomy had several maternal and neonatal benefits such as reduced risk of perineal trauma, better wound healing, reduced risk of subsequent pelvic floor dysfunction, prolapse, urinary incontinence, fecal incontinence, sexual dysfunction and decreased chance of fetal asphyxia, cranial trauma, cerebral haemorrhage and mental retardation.

However the practice of routine episiotomy was introduced without strong scientific evidence of its effectiveness and its efficacy was questioned in $1980 .^{1}$ With the publication of several descriptive and analytical papers assessing the effectiveness of episiotomy in preventing deep perineal lacerations (third and fourth degree), it was determined that, paradoxically, instead of playing a protective role for those events, episiotomy actually favored their occurrence. ${ }^{2}$ So the policy of 'selective' use of episiotomy was introduced where the use of episiotomy is restricted rather than universally performed. In this policy clinicians use their clinical judgement to determine the need for episiotomy in conditions such as impending severe perineal tear, prolonged second stage of labour, shoulder dystocia, instrumental delivery, and non-reassuring fetal heart rate. Current evidence suggests that in women where no instrumental delivery is intended, selective episiotomy policies result in fewer women with severe perineal/vaginal trauma. ${ }^{3}$ 
However, the prevailing practice in our institute was routine episiotomy for delivering baby in nulliparous women. So, we felt a need to compare routine episiotomy with selective episiotomy in our set up in nulliparous women delivering at term.

\section{METHODS}

This randomized comparative trial was conducted from April 2014 to March 2015 at the Department of Gynecology and Obstetrics of Nil Ratan Sircar Medical College, Kolkata. All participants provided written informed consent before enrollment. Institutional Ethics Committee approved the protocol.

\section{Inclusion criteria}

Women were eligible for entry into the trial if they were nulliparous with a singleton pregnancy with vertex presentation at term (>37 weeks) and were allowed for vaginal delivery.

\section{Exclusion criteria}

Women were excluded from the trial if they had any such conditions like multiparity, multiple pregnancy, assisted breech delivery, non-vertex presentations including malposition, ssociated systemic diseases, BMI $>30$, maternal exhaustion, preterm deliveries, foetal macrosomia, premature rupture of membranes, vaginal delivery after caesarean (VBAC).

\section{Randomization schedule}

Randomization was done by simple randomization method using a table of random numbers (Fisher RA and Yates F). The schedule was constructed so that the number in each group would be balanced for every 10 women recruited. The group assignments were put into sealed envelopes. The envelopes were opened during the second stage of labour, and patients were assigned either to routine episiotomy or the selective episiotomy group, depending on the basis of the randomization sequence.

\section{Treatment schedule}

Under the policy of routine use of episiotomy, all nulliparous women were given an episiotomy. Under the policy of selective use of episiotomy, great restraint was observed in giving an episiotomy, for nullipara. In the group of selective episiotomies, the assistant doctors opted for an episiotomy if the woman had instrumental delivery, shoulder dystocia, and non-reassuring fetal heart rate. When indicated, only a mediolateral episiotomy was given in our hospital. In routine episiotomy group, after preparing patients by standard method, right mediolateral episiotomy was given after infiltrating the perineum with local anaesthesia (2\% xylocaine). After delivery episiotomy was stitched in layers with chromic catgut number 1. Vaginal mucosa was stitched with continuous sutures. After the delivery, in selective episiotomy group the perineum was examined to determine the presence of lateral, anterior, superficial or deep vaginal lacerations, and posterior lacerations classified as first-degree to fourth degree according to the currently accepted classification. On $3^{\text {rd }}$ postnatal day, patient was discharged and was called for follow-up on $5^{\text {th }}$ postnatal day and then after one month and three months for longterm post-partum complications. Details of each delivery were recorded in a proforma. After 24 hours of delivery, women were interviewed and perineal pain was evaluated using a visual pain scale and the need for analgesics was assessed. Visual analogue scale (VAS) for pain is a continuous scale comprised of a horizontal (HVAS) or vertical (VVAS) line, usually 10 centimeters $(100 \mathrm{~mm})$ in length anchored by "no pain" (score of 0 ) and "pain as bad as it could be" or "worst imaginable pain" (score of 10). Subject is asked: On a scale of 0 to 10 , with 0 being no pain and 10 being the worst pain imaginable, what you rate your current pain?

For dyspareunia, women were asked if they had sexual intercourse during the last 4 weeks. Dyspareunia was considered as present when a woman gave an affirmative answer to the question' was sexual intercourse painful during the last couple of times? For ano-rectal incontinence participants were asked if there was any inability to control passage of faeces or flatus during the last 3 months of puerperium. For urinary incontinence participants were asked, 'how often do you leak urine involuntarily? Incontinence was considered present whenever the participant gave the answer other than never.

\section{Outcome measures}

Our primary outcome measures were anterior vaginal trauma, $1^{\text {st }}$ degree perineal tear, $2^{\text {nd }}$ degree perineal tear, $3^{\text {rd }}$ degree perineal tear, $4^{\text {th }}$ degree perineal tear and Apgar score at 1 and 5 minutes. Secondary measures of outcome included consumption of analgesics, anal incontinence, urinary incontinence and dyspareunia.

\section{Statistical analysis}

Continuous variables with a normal distribution were summarized using the mean. The Student T test was used for comparing population characteristics for the normally distributed continuous variables. Categorical variables were expressed as percentages. The Chi square test was used for comparing categorical variables. $\mathrm{P}$ value of $<0.05$ was considered significant. Yate's correction applied in those tests where any of the cell value was $<5$.

\section{RESULTS}

A total number of 463 women were assessed for eligibility, 286 women were eligible and 177 women were found not eligible. 286 women were enrolled for the study and were randomised. 86 women had to undergo 
emergency caesarean delivery following randomisation and excluded from final analysis. 200 women, 100 in routine episiotomy group and 100 in selective episiotomy group were analysed (Figure 1). The two groups of women were similar with regard to control variables (Table 1) and there were no statistically significant differences between the groups.

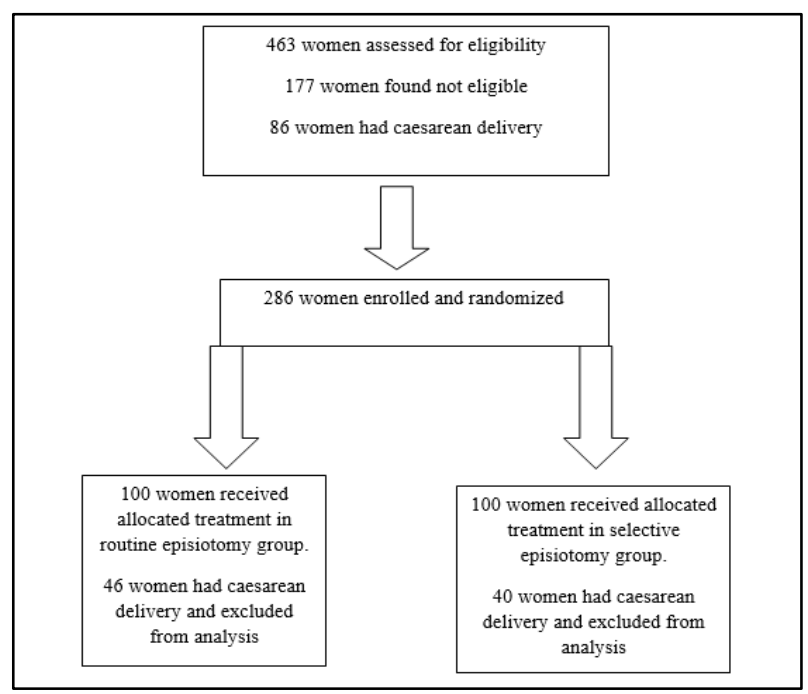

Figure 1: Trial profile.

Table 1: Showing baseline characteristics.

\begin{tabular}{|llll|}
\hline Variables & $\begin{array}{l}\text { Routine } \\
\text { episiotomy } \\
\text { group } \\
(\mathbf{n = 1 0 0 )}\end{array}$ & $\begin{array}{l}\text { Selective } \\
\text { episiotomy } \\
\text { group } \\
(\mathbf{n = 1 0 0 )}\end{array}$ & P value* \\
\hline $\begin{array}{l}\text { Age } \pm \text { SD** } \\
\text { (years) }\end{array}$ & $23.71 \pm 2.21$ & $23.54 \pm 2.51$ & 0.611 \\
\hline Religion & & & \\
\hline Hindu & 56 & 54 & 0.924 \\
\hline Muslim & 42 & 46 & 0.749 \\
\hline Others & 02 & 0 & 0.797 \\
\hline Social status & & & 0.130 \\
\hline Low & 66 & 70 & 0.544 \\
\hline Middle & 44 & 30 & \\
\hline $\begin{array}{l}\text { Birth } \\
\text { weight } \pm \text { SD (kg) }\end{array}$ & $3.02 \pm 0.36$ & $2.98 \pm 0.41$ & \\
\hline
\end{tabular}

$* \mathrm{P}$ value $\chi^{2}$ test and $\mathrm{z}$ test; $\mathrm{SD}^{* *}$ - Standard deviation

\section{Primary outcome}

Results for the primary outcome variable, are presented in (Table 2). As can be seen more women in selective episiotomy group had anterior vaginal wall tear and firstdegree perineal tear and more women in routine episiotomy group had second degree perineal injury because of obvious reason. Only 3 women in routine episiotomy group delivered with intact perineum while 15 women in selective episiotomy group delivered with intact perineum. The difference between routine episiotomy group and selective episiotomy group was statistically significant $(\mathrm{p}=0.006)$ There was no difference in occurrence of $3^{\text {rd }}$ degree perineal tear and in Apgar score among the two groups. None of the women in either group had fourth degree perineal tear.

Table 2: Primary outcome measures.

\begin{tabular}{|c|c|c|c|}
\hline Variables & $\begin{array}{l}\text { Routine } \\
\text { episiotomy } \\
\text { group } \\
(\mathbf{n}=100)\end{array}$ & $\begin{array}{l}\text { Selective } \\
\text { episiotomy } \\
\text { group } \\
(\mathbf{n}=\mathbf{1 0 0})\end{array}$ & P value* \\
\hline $\begin{array}{l}\text { Anterior vaginal } \\
\text { wall tear }\end{array}$ & 22 & 54 & $<0.0001$ \\
\hline $\begin{array}{l}\text { First degree } \\
\text { perineal tear }\end{array}$ & 05 & 16 & 0.021 \\
\hline $\begin{array}{l}\text { Second degree } \\
\text { perineal tear }\end{array}$ & 90 & 64 & $<0.0001$ \\
\hline $\begin{array}{l}\text { Third degree } \\
\text { perineal tear }\end{array}$ & 02 & 05 & 0.442 \\
\hline \multicolumn{4}{|l|}{ Apgar score } \\
\hline 1 min. $<7$ & 09 & 13 & 0.498 \\
\hline 5 min. $<7$ & 04 & 07 & 0.535 \\
\hline
\end{tabular}

\section{Secondary outcome}

Secondary outcome measures are shown in Table 3. As can be seen more women in routine episiotomy group used in analgesics on day 5 of delivery in comparison to selective episiotomy group. There was no difference in severity of perineal pain assessed by VAS, analgesic use on day 2 of delivery, anal incontinence, urinary incontinence, NICU admission of the neonate. 25 women $(25 \%)$ from routine episiotomy group and 38 women (38\%) from selective episiotomy group resumed coitus within 4 weeks. Out of 25 women in routine episiotomy group $21(84 \%)$ women complained of dyspareunia while $26(68.42 \%)$ women out of 38 women in selective episiotomy group complained of dyspareunia. The difference was not statistically significant $(\mathrm{p}=0.07)$.

Table 3: Secondary outcome measures.

\begin{tabular}{|lllll|}
\hline Measures & $\begin{array}{l}\text { Routine } \\
\text { episiotomy } \\
\text { group } \\
(\mathbf{n = 1 0 0})\end{array}$ & $\begin{array}{l}\text { Selective } \\
\text { episiotomy } \\
\text { group } \\
(\mathbf{n = 1 0 0 )}\end{array}$ & $\begin{array}{l}\mathbf{P} \\
\text { value* }\end{array}$ \\
\hline Perineal pain & & & \\
\hline $\begin{array}{l}\text { VAS** } \quad<6 \\
\text { score }\end{array}$ & 39 & 53 & 0.065 \\
\hline $\begin{array}{l}\text { Analgesic use on day } \\
\text { 2 }\end{array}$ & 61 & 47 & 0.114 \\
\hline $\begin{array}{l}\text { Analgesic use on day } \\
\text { 5 }\end{array}$ & 65 & 92 & 0.022 \\
\hline $\begin{array}{l}\text { Anal incontinence } \\
\text { (flatus) }\end{array}$ & 7 & 48 & 0.33 \\
\hline Urinary incontinence & 15 & 3 & 0.456 \\
\hline NICU admission & 6 & 9 & 0.591 \\
\hline
\end{tabular}

$* \mathrm{X}^{2}$ test $* *$ Visual Analog Scale 


\section{DISCUSSION}

100 women in routine episiotomy group and 100 women in selective episiotomy group received allocated treatment. The episiotomy rate was $90 \%$ in routine episiotomy group as 10 mothers delivered prior to episiotomy. In selective episiotomy group the episiotomy rate was $42 \%$. An update of the Cochrane systemic review, which considers recent published and unpublished studies of good quality around the world, indicates the rate of the intervention, selective episiotomy, ranged from $8 \%$ to $59 \%$ whereas the rate of the comparator, routine episiotomy, ranged from $61 \%$ to $100 \% .^{3}$

In selective episiotomy group the episiotomy rate was $42 \%$ and additional $22 \%$ women suffered from $2^{\text {nd }}$ degree perineal tear. Thus, occurrence of second-degree perineal injury was more common in routine episiotomy group (90\% versus 64\%; $\mathrm{p}<0.0001)$. However, there was no difference in occurrence of $3^{\text {rd }}$ degree perineal tear among the groups. On the other hand, more women in selective episiotomy group had intact perineum when compared with routine episiotomy group (3\% versus $15 \%$, $\mathrm{p}=0.006$ ). This finding is in agreement with the findings of recent Cochrane review that for women where an unassisted vaginal birth was anticipated, a policy of selective episiotomy may result in $30 \%$ fewer women experiencing severe perineal/vaginal trauma (RR 0.70, 95\% CI 0.52 to 0.94 ; 5375 women; eight RCTs; lowcertainty evidence). ${ }^{3}$ From neonatal point, there was no difference in Apgar score at 1 minute and at 5 minute of the babies born in two groups. Both selective and routine episiotomy have little or no effect on infants with Apgar score less than seven at five minutes (four trials, no events; 3908 women, moderate-certainty evidence. ${ }^{3}$

In our study more women in selective episiotomy group suffered from anterior vaginal wall tear (22\% versus 54\% $\mathrm{p}<0.0001)$. This finding is consistent with the randomized control trial by Argentine Episiotomy Trial Collaborative Group in 1993 involving 2606 women. ${ }^{4}$

Our study shows there was no difference in occurrence of anal incontinence, dyspareunia, urinary incontinence among the groups. In 2005, Hartmann and colleagues analyzed 45 primary studies in their systematic review on outcomes of routine episiotomy analysis proved that there were no improvements in continence of urine or stools or in pelvic floor muscle function among women who had had episiotomy compared to those who had not. ${ }^{5}$

While the strength of our study was randomized design, the main limitation of our study was that patient allocation among the groups was not blinded. However, different attending physicians with no connection to the research group were in charge of the clinical care of the patients and the group in which the patient was allocated was known only during the second stage of labor.

\section{CONCLUSION}

In conclusion, routine mediolateral episiotomy is associated with a higher incidence of perineal injuries without any added benefit for the mother and her baby and as perineal injuries known to have morbidities selective episiotomy use is therefore recommended.

\section{ACKNOWLEDGMENTS}

We are grateful to all women, the doctors, nurses, trainees and other staffs of our hospital without whose collaboration this study would not have been possible.

\section{Funding: No funding sources}

Conflict of interest: None declared

Ethical approval: The protocol for the research project had been approved by Ethics Committee of our institution (NRS Medical College) within which the work was undertaken

\section{REFERENCES}

1. Hewage SA, Abeysena C, Ziard H, Rishard M. Does routine episiotomy for vaginal births prevent major degree perineal tears? Summary of the evidence and its application to Sri Lanka. J Postgrad Inst Med. 2018;5(2):E761-7.

2. Rodriguez A, Arenas EA, Osorio AL, Mendez O, Zuleta JJ. Selective vs routine midline episiotomy for the prevention of third-or fourth-degree lacerations in nulliparous women. Am J Obstet Gynecol. 2008;198(3):285-e1.

3. Jiang H, Qian X, Carroli G, Garner P. Selective versus routine use of episiotomy for vaginal birth. Cochrane Database Systemat Rev. 2017;2:CD000081.

4. Belizan J, Campodonica L, Carroli G, Gonzalez L, Lede R, Palermo M, et al. Routine versus selective episiotomy: a randomised controlled trial. Argentine Episiotomy Trial Collaborative Group. Lancet. 1993;342(8886-8887):1517-8.

5. Hartmann K, Viswanathan M, Palmieri R, Gartlehner G, Thorp J, Lohr KN. Outcomes of routine episiotomy: a systematic review. J Am Medic Assoc. 2005;293(17):2141-8.

Cite this article as: Giri DK, Mondal D, Chaudhuri S. Routine episiotomy versus selective episiotomy in nulliparous women at term- randomized comparative trial. Int J Reprod Contracept Obstet Gynecol 2020;9:5019-22. 